\title{
Assessment of Predicted Rate and Associated Factors of Dabigatran- induced Bleeding Events in Malaysian Patients with Non-Valvular Atrial Fibrillation
}

\author{
Semira Abdi Beshir ${ }^{1}$, Lok Bin Yap ${ }^{2}$, Szyuin Sim ${ }^{1}$, Kok Han Chee ${ }^{3}$, Yoke Lin Lo ${ }^{1,4}$ \\ ${ }^{1}$ Department of Pharmacy, Faculty of Medicine, University of Malaya, Kuala Lumpur, Malaysia; ${ }^{2}$ National Heart Institute, \\ Kuala Lumpur, Malaysia; ${ }^{3}$ Department of Medicine, Faculty of Medicine, University of Malaya, Kuala Lumpur, Malaysia; \\ ${ }^{4}$ School of Pharmacy, International Medical University, Kuala Lumpur, Malaysia
}

Received, July 9, 2017; Revised, October 12, 2017; Accepted, October 13, 2017, Published, October 15, 2017.

\begin{abstract}
Purpose: To assess the predicted rate and the factors associated with bleeding events among patients with non-valvular atrial fibrillation (NVAF) receiving dabigatran therapy. Methods: This retrospective cohort study includes adult patients of two tertiary hospitals in Malaysia. Potential study subjects were identified using pharmacy supply database or novel oral anticoagulant (NOAC) registry. Demographics, clinical data and laboratory test results were extracted from the medical records of the patients or electronic databases. The main outcome measure is the occurrence of a bleeding event. Bleeding events were classified into major bleeding, clinically relevant non-major bleeding, or minor bleeding, according to the International Society on Thrombosis and Haemostasis criteria. We consider clinically relevant non-major bleeding events or major bleeding events as clinically relevant bleeding events. An occurrence of any bleeding event was recorded from the initiation of NOAC therapy until the death of a patient, or the date of permanent discontinuation of NOAC use, or the last day of data collection. The predicted rate of dabigatran-induced bleeding events per 100 patient-years was estimated. Results: During a median follow-up period of 18 months, 73 patients experienced 90 bleeding events. Among these patients, 25 including 4 fatal cases, experienced major bleeding events. The predicted rate per 100 patientyears of follow-up of any bleeding events was 9.0 [95\% CI 6.9 to 11.1]; clinically relevant bleeding events 6.0 [95\% CI 4.8 to 8.3], and major bleeding events 3.0 [95\% CI 1.9 to 4.2]. The independent risk factor for clinically relevant bleeding events is prior bleeding. While prior bleeding or congestive heart failure is linked with major bleeding events. Conclusions: The predicted rate for dabigatran-induced major bleeding episodes is low but these adverse events carry a high fatality risk. Preventive measures should target older patients who have prior bleeding or congestive heart failure.
\end{abstract}

This article is open to POST-PUBLICATION REVIEW. Registered readers (see "For Readers") may comment by clicking on ABSTRACT on the issue's contents page.

\section{INTRODUCTION}

Novel oral anticoagulants (NOACs), such as dabigatran, rivaroxaban, apixaban and edoxaban are approved as an alternative agent to warfarin for the indication of stroke prevention in patients with nonvalvular atrial fibrillation (NVAF) (1). NOACs are more likely to be prescribed to younger patients, patients with a lower estimated risk of stroke or a lower risk of bleeding, and those who are not on clopidogrel therapy than warfarin (2). Bleeding events are the most common adverse effect of NOAC therapy (3-6). These NOAC-induced bleeding events can be costly (7), inconvenient or fatal $(8 ; 9)$. Comparable rates of major bleeding associated with dabigatran and warfarin use are noted $(5 ; 6 ; 10-13)$.
In some studies, dabigatran may result in a lower (14-16), or a higher event rate of major bleeding than warfarin (17).

Various underlying factors may increase the risk of dabigatran-induced bleeding events. For example, older adults $(13 ; 18 ; 19)$, or patients with renal impairment $(20 ; 21)$ are at an increased risk of developing dabigatran-induced bleeding. Asian dabigatran users, however, seem to have a better safety profile than non-Asian users (22-24).

Corresponding Author: Yoke Lin Lo, School of Pharmacy, International Medical University, Kuala Lumpur, Malaysia; email: yokelinlo@imu.edu.my or yokelinlo@gmail.com 
Similar to other NOACs, dabigatran is linked with a lower risk of intracranial bleeding events than warfarin $(17 ; 25-28)$. Dabigatran, however, is associated with an increased $(3 ; 8 ; 12 ; 25 ; 26)$, or a similar risk of gastrointestinal bleeding events when compared to warfarin $(24 ; 29 ; 30)$.

Recent advance in drug development and evidence-based practice have made NOAC use safer. Lately, idaricuzimab was identified as an antidote to dabigatran (31). Practical guideline on NOAC use was published (1). Nonetheless, managing patients receiving dabigataran therapy remains challenging because of potentially fatal bleeding complications, limited availability of antidote and few encounters to reinforce the safe use of the drug (32).

There are limited data on the safety of NOACs in Malaysian population (33). Therefore, we aimed to determine the predicted rate of dabigatran-induced bleeding events, and to identify potential factors associated with these adverse events. We chose to include patients on dabigatran because the drug is the most widely used NOAC for stroke prevention among Malaysian patients.

\section{METHODS}

\section{Design and participants}

This retrospective cohort study involves patients with NVAF receiving dabigatran for stroke prevention between January 2010 and December 2014 at the University of Malaya Medical Centre (UMMC) and the Institute Jantung Negara (IJN or the National Heart Institute) of Malaysia. Institutional medical ethics approvals were obtained at both sites.

\section{Data collection, analyses and outcomes}

The names and registration numbers of patients who received dabigatran therapy were identified from the pharmacy supply database of UMMC and the NOAC registry of IJN. A list of potential study subjects was sent to the Patient Information Service Centre for the retrieval of their medical records. Patients with $\mathrm{NVAF}$, aged at least 18 years old, and received dabigatran were eligible to be included. Patients with no documented follow-up information, or patients with active liver disease or severe renal impairment (requiring dialysis or kidney transplant) or patients whose medical records are not traceable were excluded.

The demographics and clinical information were gathered retrospectively from medical folders or electronic medical records of the patients. Data collection was carried out between the beginning of June 2014 and the end of September 2016.

An occurrence of a bleeding event is the main outcome measure. We extracted this information from documented patient self-reports during outpatient visits, records of ward admissions, the Department of Accident and Emergency admissions at either hospitals or referral letters from other healthcare centers to the UMMC or IJN.

The stroke risk of the study subjects at the initiation of NOAC therapy was estimated using $\mathrm{CHA}_{2} \mathrm{DS}_{2}$-VASc risk score (34). In addition, HASBLED risk score was used to assess a one-year major bleeding risk of a patient (35). The estimated glomerular filtration rate (eGFR) was calculated using the Modification of Diet in Renal Disease (MDRD) formula (36). Renal impairment is defined as an eGFR of $<60 \mathrm{~mL} / \mathrm{min} / 1.73 \mathrm{~m}^{2}$ for more than three months with or without kidney damage or diagnosed chronic kidney disease (37). Liver impairment is defined as chronic hepatic disease (such as cirrhosis) or significant hepatic derangement as evidenced by serum alanine aminotransferase or aspartate aminotransferase of three times higher than the upper limits, or bilirubin two times more than the upper limit (35).

The main outcome measure of this study is an occurrence of a bleeding event. Bleeding events are defined according to the International Society on Thrombosis and Haemostasis (ISTH) criteria, and are classified into three categories: major, minor and clinically relevant non-major bleeding events (38; 39).

A major bleeding (MB) event is defined as "a fatal bleeding, and/or symptomatic bleeding in a critical area or organ, such as intracranial, intraspinal, intraocular, retroperitoneal, intraarticular or pericardial, or intramuscular with compartment syndrome, and/or bleeding causing a fall in hemoglobin level of $20 \mathrm{~g} \mathrm{~L}^{-1}\left(1.24 \mathrm{mmol} \mathrm{L}^{-1}\right)$ or more, or leading to transfusion of two or more units of whole blood or red cells" (38). Clinically relevant non-major bleeding events is a bleeding event which cannot be categorized as a major bleeding, but requires medical interventions, unscheduled visits to healthcare facility, and leads to a temporary interruption of anticoagulant therapy, or any other discomfort or impairment of activities of daily living (39). On the other hand clinically relevant bleeding event refers to major bleeding 
events and clinically relevant non-major bleeding events.

Those patients who experienced a bleeding episode, whether it was a major, minor or clinically relevant non-major bleeding event, were included in the sub-group of "Patients with any bleeding events". An occurrence of a bleeding event was recorded from the initiation of NOAC therapy until the death of a patient, or the date of permanent discontinuation of NOAC use, or the last day of data collection. The secondary outcome is an estimation of a cumulative hazard rate of any dabigatraninduced bleeding event.

\section{STATISTICAL ANALYSIS}

Frequency (proportion) was used to summarize categorical variables, while mean and standard deviation or median and range (where applicable) were used to summarize continuous variables related to patient data during the baseline analysis. An odds ratio was estimated using a binary logistic regression to assess each risk factor so as to identify the predictors associated with a first clinically relevant bleeding event. Those variables with a significant association with bleeding events in univariate analyses with a $P$ value $<0.05$, were further analyzed using multivariate logistic regression models to determine the adjusted odds ratios, and the 95\% confidence intervals for the factors associated with bleeding events (40). Nelson-Aalen cumulative hazard rates of the first episode of bleeding events were generated using package 'Survival' (41) from the R programming language (40). In R, the NelsonAalen estimate of cumulative hazard rate is obtained by specifying type="aalen" option in the Survfit() command which gives the estimate of the negative $\log$ of survival function. A predicted rate of bleeding events per 100 patient-years was estimated using package 'OpenEpi' (42).

\section{RESULTS}

Five hundred and twenty two patients were screen, and 478 patients with NVAF receiving dabigatran were included in this study. A flow chart describing the identification and selection of study subjects according to the Strengthening the Reporting of Observational Studies in Epidemiology (STROBE) statement guideline (43) is shown in Figure 1.

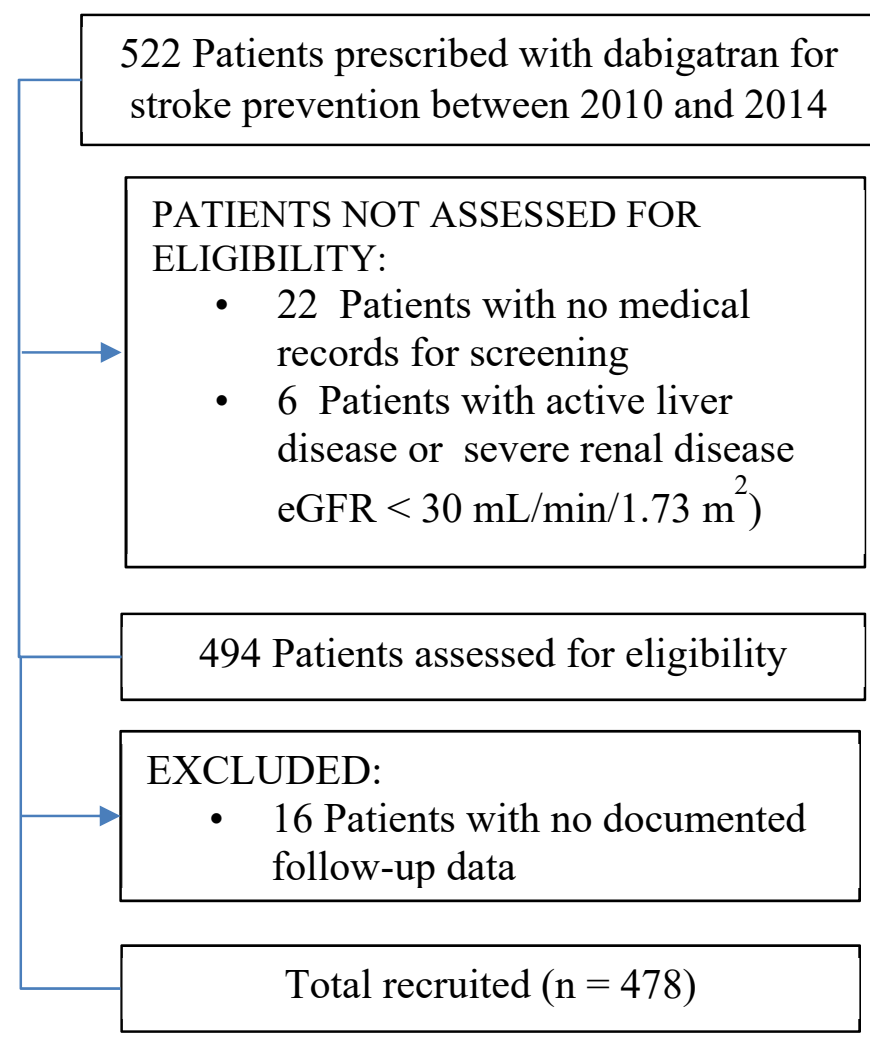

Figure 1. A flow chart describing the identification and selection of study subjects according to the STROBE statement guideline. 
Most of the study subjects were naive dabigatran users. Majority were male patients of Chinese descent. Most of the patients had a high calculated stroke risk at baseline. Hypertension was the most common stroke risk factor. The baseline characteristics of all patients and subgroups of patients without any bleeding event, patients with a first bleeding event, or major bleeding event or clinically relevant bleeding event are summarized in Table 1.

Table 1. Baseline characteristics of all patients

\begin{tabular}{|c|c|c|c|c|c|}
\hline \multirow[t]{2}{*}{ Patient characteristics } & \multirow{2}{*}{$\begin{array}{l}\text { All patients } \\
\qquad n=478\end{array}$} & \multicolumn{4}{|c|}{ Bleeding } \\
\hline & & $\begin{array}{c}\text { None } \\
\mathrm{n}=405\end{array}$ & $\begin{array}{c}\text { Any } \\
\mathrm{n}=73\end{array}$ & $\begin{array}{l}\text { Major } \\
\mathrm{n}=25\end{array}$ & $\begin{array}{c}\text { Clinically relevant } \\
\mathrm{n}=53\end{array}$ \\
\hline$\dagger$ Age in years, median (Range) & $70(30-91)$ & $69(30-91)$ & $73(42-90)$ & $70(42-90)$ & $72(42-90)$ \\
\hline$<65$ & $144(30)$ & $121(30)$ & $23(32)$ & $8(32)$ & $20(38)$ \\
\hline$\geq 65$ to $<75$ & $185(39)$ & $166(41)$ & $19(26)$ & $7(28)$ & $12(23)$ \\
\hline$\geq 75$ & $149(31)$ & $118(29)$ & $31(43)$ & $10(40)$ & $21(40)$ \\
\hline \multicolumn{6}{|l|}{ Sex } \\
\hline Male & $251(53)$ & $208(51)$ & $43(59)$ & $15(60)$ & $32(60)$ \\
\hline Female & $227(48)$ & $197(49)$ & $30(41)$ & $10(40)$ & $21(40)$ \\
\hline \multicolumn{6}{|l|}{ Race } \\
\hline Chinese & $247(52)$ & $207(51)$ & $40(55)$ & $15(60)$ & $31(58)$ \\
\hline Malay & $179(37)$ & $152(38)$ & $27(37)$ & $9(36)$ & $18(34)$ \\
\hline Indian & $52(11)$ & $46(11)$ & $6(8)$ & $1(4)$ & $4(8)$ \\
\hline \multicolumn{6}{|l|}{ Smoking status } \\
\hline Non-smokers & $426(89)$ & $362(89)$ & $64(88)$ & $20(80)$ & $46(87)$ \\
\hline Smokers & $37(8)$ & $33(8)$ & $4(6)$ & $2(8)$ & $3(6)$ \\
\hline Ex-smokers & $15(3)$ & $10(3)$ & $5(7)$ & $3(12)$ & $4(8)$ \\
\hline Alcohol drinkers & $12(3)$ & $11(3)$ & $1(1)$ & $1(4)$ & $1(2)$ \\
\hline \multicolumn{6}{|l|}{ Medical history } \\
\hline Hypertension & $377(79)$ & $317(78)$ & $60(82)$ & $21(84)$ & $45(85)$ \\
\hline Diabetes mellitus & $184(38)$ & $154(38)$ & $30(41)$ & $10(40)$ & $25(47)$ \\
\hline $\mathrm{CCF}$ & $100(21)$ & $79(20)$ & $21(29)$ & $11(44)$ & $17(32)$ \\
\hline Prior stroke/TIA & $107(22)$ & $85(21)$ & $22(30)$ & $8(32)$ & $17(32)$ \\
\hline Liver disease & $67(14)$ & $57(14$ & $10(14)$ & $5(20)$ & $8(15)$ \\
\hline Renal impairment & $178(38)$ & $136(34)$ & $32(44)$ & $10(40)$ & $28(53)$ \\
\hline †eGFR $\left(\mathrm{mL} / \mathrm{min} / 1.73 \mathrm{~m}^{2}\right)$ & $67(30-210)$ & $67(30-210)$ & $65(30-156)$ & $67(36-116)$ & $65(30-116)$ \\
\hline Missing SCR & $7(2)$ & $7(2)$ & $0(0)$ & $0(0)$ & $0(0)$ \\
\hline Malignancy & $25(5)$ & $20(5)$ & $5(7)$ & $2(8)$ & $4(8)$ \\
\hline Prior bleeding & $19(4)$ & $11(3)$ & $8(11)$ & $6(24)$ & $8(15)$ \\
\hline $\begin{array}{l}\text { Anemia }(\mathrm{Hgb}<130 \mathrm{~g} / \mathrm{L} \text { in } \\
\text { men, }<120 \mathrm{~g} / \mathrm{L} \text { in women })\end{array}$ & $141(70)$ & $113(28)$ & $28(38)$ & $11(44)$ & $23(42)$ \\
\hline Missing Hgb data & $27(5)$ & $23(32)$ & $4(6)$ & $1(4)$ & $1(2)$ \\
\hline Peptic ulcer disease & $43(9)$ & $32(8)$ & $11(15)$ & $4(16)$ & $8(15)$ \\
\hline High fall risk & $24(5)$ & $18(4)$ & $6(8)$ & $3(12)$ & $4(8)$ \\
\hline \multicolumn{6}{|l|}{ Stroke and bleeding risk } \\
\hline$\dagger \mathrm{CHA}_{2} \mathrm{DS}_{2}-\mathrm{VASc}$ score & $3(0-8)$ & $3(0-8)$ & $4(1-8)$ & $4(1-8)$ & $4(1-8)$ \\
\hline$\dagger$ HAS-BLED score & $2(0-5)$ & $2(0-5)$ & $2(0-5)$ & $2(0-4)$ & $2(0-4)$ \\
\hline \multicolumn{6}{|l|}{ Medication } \\
\hline Concomitant aspirin use & $156(33)$ & $129(32)$ & $27(37)$ & $11(44)$ & $19(36)$ \\
\hline Concomitant clopidogrel use & $102(21)$ & $83(21)$ & $19(26)$ & $7(28)$ & $14(26)$ \\
\hline
\end{tabular}


Table 1 Continued...

\begin{tabular}{|c|c|c|c|c|c|}
\hline $\begin{array}{l}\text { Concomitant ACEIs use } \\
\text { Concomitant ARB use }\end{array}$ & $\begin{array}{l}139(29) \\
120(25)\end{array}$ & $118(29)$ & $\begin{array}{l}21(29) \\
17(23)\end{array}$ & $\begin{array}{l}8(32) \\
5(20)\end{array}$ & $15(28)$ \\
\hline Prior warfarin use & $120(25)$ & $105(26)$ & $15(21)$ & $6(24)$ & $11(21)$ \\
\hline \multicolumn{6}{|l|}{ Dabigatran dosage regimen } \\
\hline Dabdigatran $75 \mathrm{mg}$ bd & $15(3)$ & $11(3)$ & $4(6)$ & $2(8)$ & $3(6)$ \\
\hline Dabigatran $110 \mathrm{mg}$ bd & $226(47)$ & $189(47)$ & $37(51)$ & $13(52)$ & $28(53)$ \\
\hline Dabigatran $150 \mathrm{mg}$ bd & $237(50)$ & $205(51)$ & $32(44)$ & $10(40)$ & $22(42)$ \\
\hline
\end{tabular}

Abbreviations: †data presented as median and range, CCF, congestive cardiac failure; TIA, transient ischemic attack; eGFR, estimated Glomerular Filtration Rate; Hgb, hemoglobin; $\mathrm{CHA}_{2} \mathrm{DS}_{2}-\mathrm{VAS}_{\mathrm{C}}$, Congestive heart failure, Hypertension, Age $\geq 75$ years, Diabetes, previous Stroke, Vascular disease, Age 65-74 years, Sex category; HAS-BLED, Hypertension, Abnormal renal or liver function, Stroke, Bleeding, Labile INR, Elderly, Drugs or alcohol abuse; ACEIs, Angiotensin-Converting Enzyme Inhibitors; ARB, Angiotensin II Receptor Blockers; bd, twice daily. Note: Clinically relevant bleeding event includes both major bleeding and clinically relevant non-major bleeding event.

During a median follow-up period of 18 months (ranged from 3 days to 65 months), 73 patients experienced 90 bleeding events. Most of the patients had bleeding events which were considered to be directly related to dabigatran therapy. Nineteen patients had other possible causes of the bleeding events such as peptic ulcer disease, fall, respiratory infections, hemorrhoids, enlarged prostate surgery, other medical procedures and high blood pressure. Of the 25 major bleeding events, 4 led to deaths within 30 days after the bleeding episode (Table 2).

Of the 73 patients who experienced a first bleeding event, 55 restarted dabigatran therapy. Eighteen patients, including four who died, stopped dabigatran permanently. Among those who discontinued dabigatran, seventeen had a $\mathrm{CHA}_{2} \mathrm{DS}_{2}-$ VASc $\geq 2$; five received antiplatelet therapy and one received apixaban.

Using time-to-event analysis with package OpenEpi (44), the predicted first bleeding event rate per 100 patient-years of follow-up of any bleeding events was 9 [95\% CI 6.9 to 11.1]; clinically relevant bleeding events, 6.0 [95\% CI 4.8 to 8.3], and major bleeding events, 3 [95\% CI 1.9 to 4.2] (Table 3).

As shown in Table 4, factors such as $\mathrm{CHA}_{2} \mathrm{DS}_{2-}$ VASc score $\geq 2$, prior bleeding, congestive heart failure, renal impairment and a HAS-BLED score $\geq$ 3 is linked with the occurrence of a first clinically relevant bleeding event. After adjusting for all factors which are associated with clinically relevant bleeding events in the univariate analysis, only prior bleeding emerged as an independent risk factor.

On the other hand, prior bleeding, congestive heart failure, $\mathrm{CHA}_{2} \mathrm{DS}_{2}$-VASc score $\geq 2$, and HASBLED score $\geq 3$ were linked with an increased risk of a first major bleeding event. Among these factors, only prior bleeding and congestive heart failure show a significant association with major bleeding events in multivariate analysis (Table 5).

Table 2. Frequency, severity, and origins of bleeding events in all patients

\begin{tabular}{lc}
\hline Severity and origin of bleeding events & All patients $(\mathrm{n}=478)$ \\
\cline { 2 - 2 } Major bleeding events & Frequency of bleeding events \\
Intracranial bleeding & $25(4$ deaths $)$ \\
Gastrointestinal bleeding & 8 \\
Clinically relevant non-major bleeding events & 17 \\
Minor bleeding events & 33 \\
All bleeding events & 32 \\
\hline
\end{tabular}

Note: Among the 73 patients with bleeding events, 57 patients experienced a single bleeding event, while 16 patients had recurrent bleeding events (15 experienced 2 bleeding events, while 1 patient experienced 3 bleeding events). 
Table 3. The predicted event rate per 100 patient-years for any bleeding events, clinically relevant bleeding events, and major bleeding events

\begin{tabular}{lccc}
\hline & \multicolumn{3}{c}{ All patients $\mathbf{( N = 4 7 8 )}$} \\
\cline { 2 - 4 } & No. of events & $\begin{array}{c}\text { Patient-years under } \\
\text { risk }\end{array}$ & $\begin{array}{c}\text { Predicted event rate* per 100 } \\
\text { patient-years [95 \% Confidence } \\
\text { interval] }\end{array}$ \\
\hline Any bleeding events & 73 & 825 & $8.9[6.9-11.1]$ \\
Clinically relevant bleeding & 53 & 832 & $6.4[4.8-8.3]$ \\
Major bleeding events & 25 & 857 & $2.9[1.9-4.2]$
\end{tabular}

$*$ Event rate $=$ Number of events $\div$ total patient-time under risk. The total patient-time under risk is the sum of all days from the date of initiation of dabigatran therapy until the date of the first bleeding event or the date of discontinuation of dabigatran or the date of death or the last date of follow-up if no bleeding event occurred during the follow-up period. The event rate is scaled to a unit of 'number of bleeding events per 100 patients-years' by dividing the event rate by 365 (to convert days to years) and multiplying by 100 (to convert per patient-year to per 100 patient-years). Note: Clinically relevant bleeding event includes both major bleeding and clinically relevant non-major bleeding event.

Table 4. Predictors of clinically relevant bleeding events

\begin{tabular}{|c|c|c|c|c|c|c|}
\hline Risk factors & $\begin{array}{c}\text { Unadjusted } \\
\text { OR }\end{array}$ & $95 \% \mathrm{CI}$ & $P$ value & $\begin{array}{c}\text { Adjusted } \\
\text { OR }\end{array}$ & $95 \% \mathrm{CI}$ & P value \\
\hline Prior bleeding & 6.86 & $2.54-17.87$ & $0.001^{*}$ & 6.86 & $2.54-17.87$ & $0.001 *$ \\
\hline $\mathrm{CHA}_{2} \mathrm{DS}_{2}-\mathrm{VASc} \geq 2$ & 2.93 & $1.46-6.57$ & $0.004 *$ & 2.93 & $1.46-6.57$ & $0.004 *$ \\
\hline HAS-BLED $\geq 3$ & 1.96 & $1.06-3.55$ & $0.028^{*}$ & 1.96 & $1.06-3.55$ & $0.028^{*}$ \\
\hline Congestive heart failure & 2.01 & $1.05-3.71$ & $0.029 *$ & 2.01 & $1.05-3.71$ & $0.029 *$ \\
\hline Renal Impairment & 1.92 & $1.07-3.44$ & $0.027 *$ & 1.92 & $1.07-3.44$ & $0.027^{*}$ \\
\hline Age $\geq 75$ years & 1.47 & $0.80-2.65$ & 0.204 & 1.47 & $0.80-2.65$ & 0.204 \\
\hline Anemia & 1.73 & $0.94-3.12$ & 0.072 & 1.73 & $0.94-3.12$ & 0.072 \\
\hline Peptic ulcer disease & 1.69 & $0.66-3.81$ & 0.238 & 1.69 & $0.66-3.81$ & 0.238 \\
\hline Female sex & 0.79 & $0.44-1.41$ & 0.429 & 0.79 & $0.44-1.41$ & 0.429 \\
\hline Liver disease & 1.11 & $0.46-2.36$ & 0.800 & 1.11 & $0.46-2.36$ & 0.800 \\
\hline Prior warfarin use & 0.88 & $0.43-1.70$ & 0.721 & 0.88 & $0.43-1.70$ & 0.721 \\
\hline Concomitant aspirin use & 1.10 & $0.59-2.00$ & 0.747 & 1.10 & $0.59-2.00$ & 0.747 \\
\hline $\begin{array}{l}\text { Concomitant clopidogrel } \\
\text { use }\end{array}$ & 1.12 & $0.54-2.16$ & 0.746 & 1.12 & $0.54-2.16$ & 0.746 \\
\hline Concomitant ACEI use & 0.99 & $0.51-1.83$ & 0.969 & 0.99 & $0.51-1.83$ & 0.969 \\
\hline Concomitant ARB use & 0.78 & $0.37-1.52$ & 0.487 & 0.78 & $0.37-1.52$ & 0.487 \\
\hline $\begin{array}{l}\text { Dabigatran } 150 \mathrm{mg} \text { bd vs. } \\
\text { dabigatran } 110 \mathrm{mg} \text { bd }\end{array}$ & 0.69 & $0.37-1.25$ & 0.687 & 0.69 & $0.37-1.25$ & 0.687 \\
\hline Stroke or TIA & 1.81 & $0.95-3.34$ & 0.061 & 1.81 & $0.95-3.34$ & 0.061 \\
\hline Malignancy & 1.61 & $0.45-4.44$ & 0.402 & 1.61 & $0.45-4.44$ & 0.402 \\
\hline Hypertension & 1.54 & $0.73-3.62$ & 0.285 & 1.54 & $0.73-3.62$ & 0.285 \\
\hline Diabetes & 1.42 & $0.79-2.54$ & 0.231 & 1.42 & $0.79-2.54$ & 0.231 \\
\hline High fall risk & 1.69 & $0.48-4.70$ & 0.355 & 1.69 & $0.48-4.70$ & 0.355 \\
\hline $\begin{array}{l}\text { Abbreviations: OR, Odds } \mathrm{I} \\
\text { years, Diabetes and previo } \\
\text { renal or liver function, Str } \\
\text { Angiotensin II Receptor B }\end{array}$ & CI, Confiden & $\begin{array}{l}\text { INR; ACEI } \\
\text { Ischemic At }\end{array}$ & VASc; C & ive hear & re, Hypertens & $\begin{array}{l}\text { e } \geq 75 \\
\text { ormal } \\
\text { ARB, } \\
\text { ant). }\end{array}$ \\
\hline
\end{tabular}

No significant difference in the odds ratios of having any first bleeding events or clinically relevant bleeding events or major bleeding events was observed with $150 \mathrm{mg}$ bd or $110 \mathrm{mg}$ bd dosing regimens of dabigatran in our study.

The estimated cumulative hazard rate of any first bleeding event is moderate at $40 \%$; while that of clinically relevant bleeding events is $37 \%$, and for major bleeding events is low at $10 \%$. As displayed in Figure 2, a plot for any bleeding events over time exhibits a steeply rising curve during the early phase of dabigatran use. The curve plateaus out after about 45 months. The estimated cumulative hazard rate for clinically relevant bleeding events shows a similar 
trend of higher hazard rate during the early phase of dabigatran therapy; while that of major bleeding events show a gentler rise until about 15 months after the initiation of dabigatran therapy.

\section{DISCUSSION}

Asians have a high burden of stroke secondary to atrial fibrillation that necessitates the use of anticoagulants such as dabigatran $(23 ; 24)$. We predicted a first bleeding event rate per 100 patientyears of dabigatran-associated bleeding among Malaysian patients with NVAF, and add to the evidence of real-world dabigatran safety. A previous single center study involving Malaysian patients with NVAF receiving dabigatran with a median follow-up period of 10 months at the National Heart Institute are descriptive in nature (33). The bleeding event rate and the predictors of dabigatran-induced bleeding were not estimated nor determined. On the other hand, the current study, involves patients with NVAF from 2 referral centers (University of Malaya and the National Heart Institute), with a longer median follow-up period of 18 months. As a result, more major and clinically relevant bleeding events were observed in our study. Furthermore, more information on the dates of bleeding event occurrence were extracted to allow the "time-toevent" analysis.

The estimated rate of any first bleeding event is lower than that reported in the RE-LY trial (13). Asians have been shown to have less risk of bleeding with dabigatran than non-Asians $(22 ; 23)$. The estimated rate of a first dabigatran-induced clinically relevant bleeding event in this study is lower than that reported for rivaroxaban (14.9\% per year) and warfarin (14.5\% per year) in ROCKET-AF trial (19). The rate of a first major bleeding, however, is comparable to those reported in previous studies (5; $10 ; 11 ; 45 ; 46)$.

Table 5. Predictors of major bleeding events

\begin{tabular}{|c|c|c|c|c|c|c|}
\hline Risk factors & $\begin{array}{c}\text { Unadjusted } \\
\text { OR }\end{array}$ & $95 \% \mathrm{CI}$ & $P$ value & $\begin{array}{l}\text { Adjusted } \\
\text { OR }\end{array}$ & $95 \%$ CI & $P$ value \\
\hline Prior bleeding & 10.69 & $3.45-30.40$ & $0.0001 *$ & 9.03 & $2.81-26.75$ & $0.0001^{*}$ \\
\hline Congestive heart failure & 3.21 & $1.38-7.30$ & $0.005^{*}$ & 2.84 & $1.18-6.74$ & $0.017^{*}$ \\
\hline HAS-BLED $\geq 3$ & 2.39 & $1.03-5.41$ & $0.036^{*}$ & 1.95 & $0.80-4.62$ & 0.131 \\
\hline $\mathrm{CHA}_{2} \mathrm{DS}_{2}-\mathrm{VASc} \geq 2$ & 3.06 & $1.21-10.31$ & $0.035^{*}$ & 2.20 & $0.41-40.66$ & 0.457 \\
\hline Age $\geq 75$ years & 1.54 & $0.65-3.47$ & 0.307 & & & \\
\hline Age $\geq 65$ years & 1.10 & $0.47-2.89$ & 0.830 & & & \\
\hline Female sex & 0.73 & $0.31-1.63$ & 0.443 & & & \\
\hline Liver disease & 1.55 & $0.50-3.99$ & 0.399 & & & \\
\hline Anemia & 2.04 & $0.87-4.67$ & 0.092 & & & \\
\hline Concomitant ACEI use & 1.16 & $0.46-2.67$ & 0.741 & & & \\
\hline Concomitant ARB use & 0.73 & $0.24-1.86$ & 0.547 & & & \\
\hline Renal Impairment & 1.31 & $0.57-2.95$ & 0.512 & & & \\
\hline Prior warfarin use & 0.94 & $0.34-2.28$ & 0.896 & & & \\
\hline Concomitant aspirin use & 1.69 & $0.72-3.76$ & 0.217 & & & \\
\hline $\begin{array}{l}\text { Concomitant clopidogrel } \\
\text { use }\end{array}$ & 1.47 & $0.56-3.47$ & 0.406 & & & \\
\hline $\begin{array}{l}\text { Dabigatran } 150 \mathrm{mg} \text { bd vs. } \\
\text { dabigatran } 110 \mathrm{mg} \text { bd }\end{array}$ & 0.72 & $0.30-1.68$ & 0.450 & & & \\
\hline Peptic ulcer disease & 2.02 & $0.57-5.64$ & 0.217 & & & \\
\hline Stroke or TIA & 1.68 & $0.67-3.90$ & 0.241 & & & \\
\hline Malignancy & 1.42 & $0.46-3.63$ & 0.502 & & & \\
\hline Hypertension & 1.43 & $0.53-4.99$ & 0.521 & & & \\
\hline Diabetes & 1.07 & $0.46-2.41$ & 0.874 & & & \\
\hline High fall risk & 2.86 & $0.63-8.96$ & 0.115 & & & \\
\hline $\begin{array}{l}\text { Abbreviations: OR, Odds } \\
\text { function, Stroke, Bleeding, } \\
\text { Diabetes and previous Str } \\
\text { Enzyme Inhibitor; ARB, A } \\
\text { Vs., Versus. }{ }^{*} P \text { value }<0.0\end{array}$ & $\begin{array}{l}\text { io; CI, Confi } \\
\text { bile INR; CH } \\
\text { Vascular dis } \\
\text { tensin II Rece } \\
\text { tatistically sig }\end{array}$ & $\begin{array}{l}\text { ice Interval; } \\
\mathrm{OS}_{2} \text {-VASc, Cc } \\
\text { e, Age 65-74 } \\
\text { r Blocker; vs. } \\
\text { icant). }\end{array}$ & $\begin{array}{l}\text { BLED, H } \\
\text { tive heart } \\
\text { s, Sex cat } \\
\text { is; bd, twic }\end{array}$ & $\begin{array}{l}\text { ension, Ab } \\
\text { e, Hyperter } \\
\text {; ACEI, A } \\
\text { y; TIA, trar }\end{array}$ & $\begin{array}{l}\text { nal renal or } 1 \\
n, \text { Age } \geq 75 \text { ye } \\
\text { tensin-Conver } \\
\text { nt ischemic att }\end{array}$ & \\
\hline
\end{tabular}



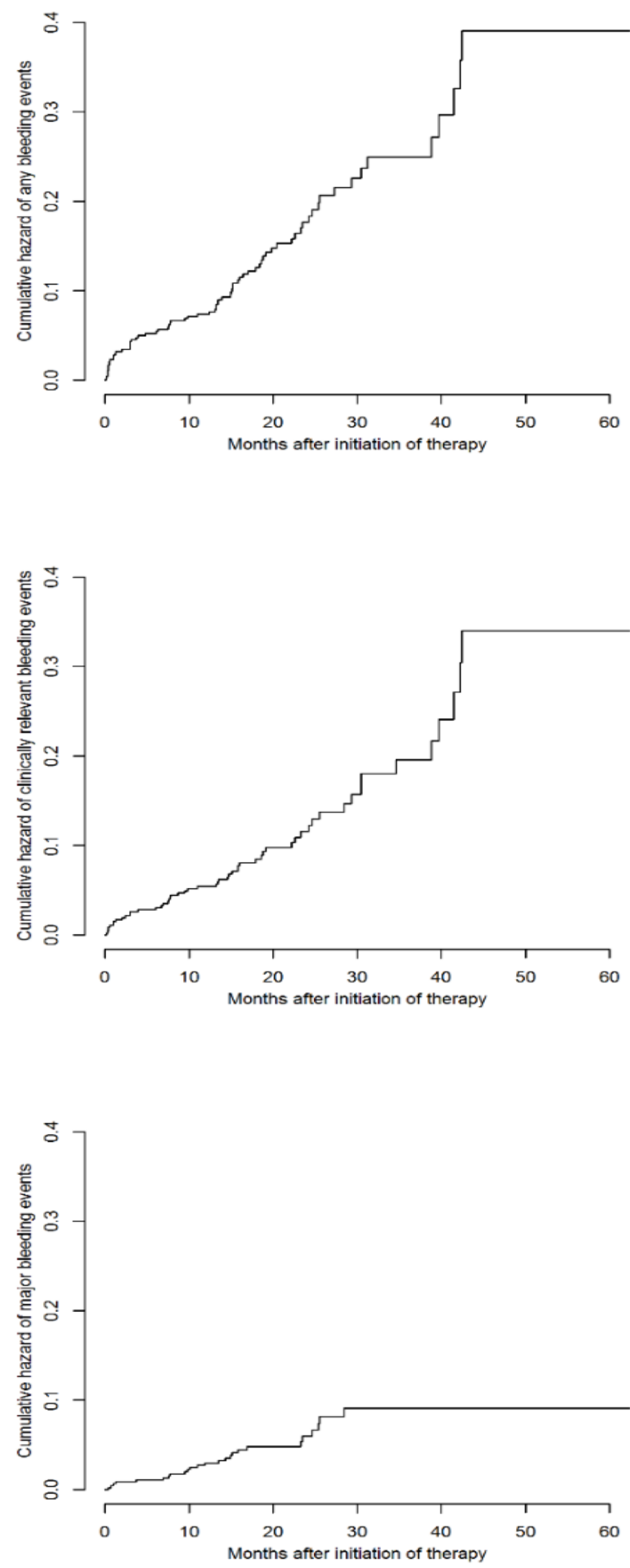

Figure 2. Estimated cumulative hazard rate function for any bleeding event (top panel), clinically relevant bleeding events (middle panel) and major bleeding events (lower panel) for all study subjects. 
Our findings show a higher hazard rate of a first bleeding event during the first 40 months of dabigatran therapy. This indicates the importance of close monitoring during the first three years of dabigatran use. As reported previously, bleeding events could lead to permanent discontinuation of dabigatran (47-49). Previous studies reported about $50 \%$ of the patients discontinued the drug because of minor or clinically relevant non-major bleeding events. Furthermore, most of those who discontinued dabigatran use are at a high risk of stroke. It is therefore crucial for those who discontinued dabigatran use to receive an alternative oral anticoagulant therapy. Nonetheless, the use of antiplatelet as an alternative to oral anticoagulant in patients with NVAF is not recommended (50).

Similar to a study by Katoh et al., (51) gastrointestinal bleeding is the most common type of major bleeding events in our cohorts. The topical activity of unabsorbed dabigatran at the gastrointestinal mucosa may be related to an increased risk of gastrointestinal bleeding (52).

Gastrointestinal or intracranial bleeding events may also be the cause of four fatal bleeding events in this study. Three of those four affected patients started on NOACs at an older age of 75 years or above. Moreover, two fatal cases had a comorbid congestive heart failure or chronic kidney disease. These risk factors may have contributed to having a major bleeding event, and subsequent death.

Unlike the findings in our study, a study by Reilly et al. involving 9,183 patients (mainly Caucasians) with $35 \%$ of them aged 75 years or above, and $3.8 \%$ major bleeding events, has identified age as an independent risk factor for a bleeding event (53). In our cohort of 478 patients (mainly Asians), only $31 \%$ aged 75 years or older, but 25 patients $(5.2 \%)$ reported to have major bleeding events. A different racial groups and a smaller sample size may made the association between age and bleeding events less apparent. Age was also not a significant predictor of bleeding events in a similar Asian study conducted among 184 Japanese dabigatran users with atrial fibrillation (51).

Congestive heart failure is also found to be associated with major bleeding events in our cohorts. This risk factor may be related to the prevalent use of nephrotoxic drugs such as angiotensin-converting enzyme inhibitors (ACEIs), or diuretics that worsen renal function in heart failure (18). Moreover, the coexistence of atrial fibrillation with congestive heart failure is associated with a poor clinical outcome and death (54).

Although a higher dose of dabigatran was reported to be linked with a higher risk of major bleeding $(13 ; 46)$, our study fails to show such linkage. Nonetheless, patients with a high risk of stroke (with a $\mathrm{CHA}_{2} \mathrm{DS}_{2}-\mathrm{VASc} \geq 2$ ) or bleeding events (with a HAS-BLED score $\geq 3$ ), were more likely to experience major bleeding events. An increased risk of major bleeding with increasing $\mathrm{CHA}_{2} \mathrm{DS}_{2}$-VASc or HAS-BLED scores has been previously described (55-58).

Renal or hepatic dysfunction may escalate the risk of bleeding (21). Nonetheless, neither of these factors shows a link with bleeding events in our study. The precautionary practice of using a lower dose of dabigatran in patients with renal dysfunction, or the avoidance of co-administration of interacting drugs during dabigatran therapy may be the reason for the lack of this association in our patients.

Due to the nature of an observational study design used, this study has some limitations and certain assumptions were made. The exposure to dabigatran is assumed as long as patients filled their prescriptions. The impact of co-administration of over-the-counter products, including non-steroidal anti-inflammatory drugs (NSAIDs) and traditional medicines on the bleeding risk of a patient could not be assessed. Finally, due to a relatively low bleeding event rate, the association between other factors and bleeding events may have become less apparent.

Despite the above-mentioned limitations, this study has highlighted the predicted rate and risk factors associated with dabigatran-induced bleeding among Malaysian patients. The findings of this study have some important implications for planning preventive measures for adverse drug events. As bleeding risk factors are dynamic, periodic assessments of the stroke risk and bleeding risk are important, especially among older adults. Tailored patient education and updating healthcare providers on the emerging data on dabigatran-associated bleeding risk factors can be useful.

\section{CONCLUSIONS}

The rate of dabigatran-associated major bleeding events is low, but these adverse events may carry a high fatality risk. Therefore, interventional programs for bleeding prevention should target older patients with congestive heart failure, prior bleeding events, $\mathrm{CHA}_{2} \mathrm{DS}_{2}$-VASc score $\geq 2$, and HAS-BLED score $\geq$ 
3, especially during the first three years of NOAC therapy.

\section{ACKNOWLEDGMENTS}

Financial disclosures: This project is supported by internal funding.

The authors would also like to thank the staff at the Department of pharmacy and the Patient Information Service Unit of the University of Malaya Medical Centre (UMMC) and the National Heart Institute of Malaysia for facilitating the retrieval and access to data of patients used in this study.

\section{CONFLICT OF INTEREST}

The authors declare no conflict of interest.

\section{REFERENCES}

1. Heidbuchel H, Verhamme P, Alings M, Antz M, Diener HC, et al. 2015. Updated European Heart Rhythm Association practical guide on the use of non-vitamin-K antagonist anticoagulants in patients with non-valvular atrial fibrillation: Executive summary. Europace : European pacing, arrhythmias, and cardiac electrophysiology : journal of the working groups on cardiac pacing, arrhythmias, and cardiac cellular electrophysiology of the European Society of Cardiology 17:1467- 507. doi: 10.1093/eurheartj/ehw058.

2. Brais C, Larochelle J, Turgeon MH, Blais L, Farand P, et al. 2017. Predictors of Direct Oral Anticoagulants Utilization for Thromboembolism Prevention in Atrial Fibrillation. Journal of Pharmacy \& Pharmaceutical Sciences : a publication of the Canadian Society for Pharmaceutical Sciences, Societe canadienne des sciences pharmaceutiques 20:8-14. doi: 10.18433/J30W4F.

3. Holster IL, Valkhoff VE, Kuipers EJ, Tjwa ET. 2013. New oral anticoagulants increase risk for gastrointestinal bleeding: a systematic review and meta-analysis. Gastroenterology 145:105-12.e15. doi: 10.1053/j.gastro.2013.02.041.

4. Larsen TB, Skjoth F, Nielsen PB, Kjaeldgaard JN, Lip GY. 2016. Comparative effectiveness and safety of non-vitamin $\mathrm{K}$ antagonist oral anticoagulants and warfarin in patients with atrial fibrillation: propensity weighted nationwide cohort study. BMJ (Clinical research ed.) 353:i3189. doi: 10.1136/bmj.i3189.

5. Lip GY, Pan X, Kamble S, Kawabata H, Mardekian J, et al. 2016. Major bleeding risk among nonvalvular atrial fibrillation patients initiated on apixaban, dabigatran, rivaroxaban or warfarin: a "real-world" observational study in the United States.
International journal of clinical practice 70:752-63. doi: 752-763. 10.1111/ijcp.12863.

6. Maura G, Blotière P-O, Bouillon $\mathrm{K}$, Billionnet $\mathrm{C}$, Ricordeau $P$, et al. 2015. Comparison of the shortterm risk of bleeding and arterial thromboembolic events in nonvalvular atrial fibrillation patients newly treated with dabigatran or rivaroxaban versus vitamin $\mathrm{k}$ antagonists: A french nationwide propensitymatched cohort study. Circulation 132:1252-60. doi: 10.1161/circulationaha.115.015710.

7. Zhao YJ, Lin L, Zhou HJ, Tan KT, Chew AP, et al. 2016. Cost-effectiveness modelling of novel oral anticoagulants incorporating real-world elderly patients with atrial fibrillation. International journal of cardiology 220:794-801. doi: 10.1016/j.ijcard.2016.06.087.

8. Graham DJ, Reichman ME, Wernecke M, Zhang R, Southworth MR, et al. 2015. Cardiovascular, Bleeding, and Mortality Risks in Elderly Medicare Patients Treated with Dabigatran or Warfarin for Non-Valvular Atrial Fibrillation. Circulation 131:157-64. doi

10.1161/circulationaha.114.012061.

9. Alonso A, Bengtson LG, MacLehose RF, Lutsey PL, Chen LY, Lakshminarayan K. 2014. Intracranial hemorrhage mortality in atrial fibrillation patients treated with dabigatran or warfarin. Stroke; a journal of cerebral circulation 45:2286-91. doi: 10.1161/STROKEAHA.114.006016. Epub 2014 Jul 3.

10. Larsen TB, Rasmussen LH, Skjøth F, Due KM, Callréus T, et al. 2013. Efficacy and Safety of Dabigatran Etexilate and Warfarin in "Real-World" Patients With Atrial FibrillationA Prospective Nationwide Cohort Study. Journal of the American College of Cardiology 61:2264-73. doi: 10.1016/j.jacc.2013.03.020.

11. O'Brien EC, Kim S, Thomas L, Fonarow GC, Kowey PR, et al. 2016. Clinical Characteristics, Oral Anticoagulation Patterns, and Outcomes of Medicaid Patients With Atrial Fibrillation: Insights From the Outcomes Registry for Better Informed Treatment of Atrial Fibrillation (ORBIT-AF I) Registry. Journal of the American Heart Association 5:e002721. doi: 10.1161/jaha.115.002721.

12. Yavuz B, Ayturk M, Ozkan S, Ozturk M, Topaloglu C, et al. 2016. A real world data of dabigatran etexilate: multicenter registry of oral anticoagulants in nonvalvular atrial fibrillation. Journal of Thrombosis and Thrombolysis 42:399-404. doi: 10.1007/s11239-016-1361-4.

13. Connolly SJ, Ezekowitz MD, Yusuf S, Eikelboom J, Oldgren J, et al. 2009. Dabigatran versus warfarin in patients with atrial fibrillation. New England Journal of Medicine 361:1139-51. doi: 10.1056/NEJMoa0905561. Epub 2009 Aug 30. 
14. Riva N, Ageno W. 2015. Direct oral anticoagulants in atrial fibrillation: can data from randomized clinical trials be safely transferred to the general population? Yes. Internal and Emergency Medicine 10:641-5. doi: 10.1007/s11739-015-1277-6.

15. Yao X, Abraham NS, Sangaralingham LR, Bellolio MF, McBane RD, et al. 2016. Effectiveness and Safety of Dabigatran, Rivaroxaban, and Apixaban Versus Warfarin in Nonvalvular Atrial Fibrillation. Journal of the American Heart Association 5:e003725. doi: 10.1161/jaha.116.003725.

16. Levi M. 2011. ACP Journal Club. Dabigatran led to less major bleeding than warfarin in younger but not older patients with atrial fibrillation. Annals of internal medicine 155:Jc3-3. doi: 10.7326/00034819-155-6-201109200-02003.

17. Hernandez I, Baik SH, Pinera A, Zhang Y. 2015. Risk of bleeding with dabigatran in atrial fibrillation. JAMA internal medicine 175:18-24. doi: 10.1001/jamainternmed.2014.5398.

18. Lauffenburger JC, Rhoney DH, Farley JF, Gehi AK, Fang G. 2015. Predictors of gastrointestinal bleeding among patients with atrial fibrillation after initiating dabigatran therapy. Pharmacotherapy 35:560-8. doi: 10.1002/phar.1597.

19. Patel MR, Mahaffey KW, Garg J, Pan G, Singer DE, et al. 2011. Rivaroxaban versus warfarin in nonvalvular atrial fibrillation. New England Journal of Medicine 365:883-91. doi: 10.1056/NEJMoa1009638. Epub 2011 Aug 10.

20. Miyamoto K, Aiba T, Arihiro S, Watanabe M, Kokubo Y, et al. 2016. Impact of renal function deterioration on adverse events during anticoagulation therapy using non-vitamin $\mathrm{K}$ antagonist oral anticoagulants in patients with atrial fibrillation. Heart and Vessels 31:1327-36. doi: 10.1007/s00380-015-0725-6.

21. Graff J, Harder S. 2013. Anticoagulant therapy with the oral direct factor xa inhibitors rivaroxaban, apixaban and edoxaban and the thrombin inhibitor dabigatran etexilate in patients with hepatic impairment. Clinical Pharmacokinetics 52:243-54. doi: 10.1007/s40262-013-0034-0.

22. Hori M, Connolly SJ, Zhu J, Liu LS, Lau C-P, et al. 2013. Dabigatran Versus Warfarin Effects on Ischemic and Hemorrhagic Strokes and Bleeding in Asians and Non-Asians With Atrial Fibrillation. Stroke; a journal of cerebral circulation 44:1891-6. doi: 10.1161/STROKEAHA.113.000990. Epub 2013 Jun 6.

23. Chiang CE, Wang KL, Lip GY. 2014. Stroke prevention in atrial fibrillation: an Asian perspective. Thrombosis and haemostasis 111:789-97. doi: 10.1160/th13-11-0948.

24. Lip GY, Wang KL, Chiang CE. 2015. Non-vitamin K antagonist oral anticoagulants (NOACs) for stroke prevention in Asian patients with atrial fibrillation: time for a reappraisal. International journal of cardiology 180:246-54. doi: 10.1016/j.ijcard.2014.11.182.

25. Eikelboom JW, Wallentin L, Connolly SJ, Ezekowitz M, Healey JS, et al. 2011. Risk of bleeding with 2 doses of dabigatran compared with warfarin in older and younger patients with atrial fibrillation an analysis of the randomized evaluation of long-term anticoagulant therapy (RE-LY) trial. Circulation 123:2363-72. 10.1161/circulationaha.110.004747.

26. Miller CS, Grandi SM, Shimony A, Filion KB, Eisenberg MJ. 2012. Meta-analysis of efficacy and safety of new oral anticoagulants (dabigatran, rivaroxaban, apixaban) versus warfarin in patients with atrial fibrillation. The American journal of cardiology 110:453-60. doi: 10.1016/j.amjcard.2012.03.049.

27. Larsen TB, Lip GYH. 2014. Warfarin or novel oral anticoagulants for atrial fibrillation? The Lancet 383:931-3. doi: http://dx.doi. org/10.1016/S01406736(13)62376-4.

28. Hicks T, Stewart F, Eisinga A. 2016. NOACs versus warfarin for stroke prevention in patients with AF: a systematic review and meta-analysis. Open Heart 3:e00279. doi: 10.1136/openhrt-2015-000279.

29. Chang H-Y, Zhou M, Tang W, Alexander GC, Singh S. 2015. Risk of gastrointestinal bleeding associated with oral anticoagulants: population based retrospective cohort study. BMJ (Clinical research ed.) 350:h1585. doi: 10.1136/bmj.h1585.

30. Abraham NS, Singh S, Alexander GC, Heien H, Haas LR, et al. 2015. Comparative risk of gastrointestinal bleeding with dabigatran, rivaroxaban, and warfarin: population based cohort study. BMJ (Clinical research ed.) 350:h1857. doi: 10.1136/bmj.h1857.

31. Pollack Jr CV, Reilly PA, Eikelboom J, Glund S, Verhamme P, et al. 2015. Idarucizumab for dabigatran reversal. New England Journal of Medicine 373:511-20. doi: 10.1056/NEJMoa1502000. Epub 2015 Jun 22.

32. Shore S, Carey EP, Turakhia MP, Jackevicius CA, Cunningham F, et al. 2014. Adherence to dabigatran therapy and longitudinal patient outcomes: Insights from the Veterans Health Administration. American heart journal 167:810-7. doi: 10.1016/j.ahj.2014.03.023.

33. Yap LB, Rusani, Beni Isman, Umadevan, Dhanan, et al. 2014. A single centre experience of the efficacy and safety of dabigatran etexilate used for stroke prevention in atrial fibrillation. Journal of thrombosis and thrombolysis 38:39-44. doi: 10.1007/s11239013-1020-y.

34. Lip GY, Nieuwlaat R, Pisters R, Lane DA, Crijns HJ. 2010. Refining clinical risk stratification for predicting stroke and thromboembolism in atrial fibrillation using a novel risk factor-based approach: 
the euro heart survey on atrial fibrillation. Chest Journal 137:263-72. doi: 10.1378/chest.09-1584. Epub 2009 Sep 17.

35. Pisters R, Lane DA, Nieuwlaat R, de Vos CB, Crijns HJ, Lip GY. 2010. A novel user-friendly score (HASBLED) to assess 1-year risk of major bleeding in patients with atrial fibrillation: the Euro Heart Survey. Chest 138:1093-100. doi: 10.1378/chest.100134. Epub 2010 Mar 18.

36. Levey AS, Coresh J, Greene T, Stevens LA, Zhang YL, et al. 2006. Using standardized serum creatinine values in the modification of diet in renal disease study equation for estimating glomerular filtration rate. Annals of internal medicine 145:247-54. doi: 10.7326/0003-4819-145-4-200608150-00004.

37. National Kidney Foundation. 2002. [Internet].Clinical practice guidelines for chronic kidney disease: evaluation, classification and stratification. 2002 [cited 2015 Aug 22] Available from:

https://www.kidney.org/sites/default/files/docs/ckd evaluation classification stratification.pdf.

38. Schulman S, Kearon C. 2005. Definition of major bleeding in clinical investigations of antihemostatic medicinal products in non-surgical patients. Journal of Thrombosis and Haemostasis 3:692-4 . doi: 10.1111/j.1538-7836.2005.01204.x.

39. Kaatz S, Ahmad D, Spyropoulos AC, Schulman S. 2015. Definition of clinically relevant non-major bleeding in studies of anticoagulants in atrial fibrillation and venous thromboembolic disease in non-surgical patients: communication from the SSC of the ISTH. Journal of thrombosis and haemostasis : JTH 13:2119-26. doi: 10.1111/jth.13140.

40. R Core Team. 2014. [Internet].Vienna (Austria). R: A language and environment for statistical computing. $\mathrm{R}$ Foundation for Statistical Computing. Version3.1.2. 2014 [cited 2015 Aug 22]. Available from: http://www.R-project.org/.

41. Therneau T. [Internet]. A package for survival analysis in S. R package version 2.37-7. [cited 2015 Aug 22]. Available from : http://CRAN.Rproject.org/package $=$ survival.

42. Dean AG SK, Soe MM.,. [Internet]. OpenEpi: Open Source Epidemiologic Statistics for Public Health, Version. wwe.OpenEpi.com, updated 2015/05/04, accessed 2015/11/05.[Cited 2015 Nov 05] Available from:http://www.openepi.com/Menu/OE_Menu.htm

43. Von Elm E, Altman DG, Egger M, Pocock SJ, Gøtzsche PC, et al. 2014. The Strengthening the Reporting of Observational Studies in Epidemiology (STROBE) Statement: guidelines for reporting observational studies. International Journal of Surgery 12:1495-9. doi: 10.1016/j.jjsu.2014.07.013. Epub 2014 Jul 18.
44. Dean AG, Sullivan KM, Soe MM. 2015. OpenEpi: Open Source Epidemiologic Statistics for Public Health, Version. wwe.OpenEpi.com. http://www.openepi.com/Menu/OE Menu.htm

45. Ezekowitz MD, Wallentin L, Connolly SJ, Parekh A, Chernick MR, et al. 2010. Dabigatran and Warfarin in Vitamin K Antagonist-Naive and -Experienced Cohorts With Atrial Fibrillation. Circulation 122:2246-53. doi: 10.1161/circulationaha.110.973735.

46. Connolly SJ, Wallentin L, Ezekowitz MD, Eikelboom J, Oldgren J, et al. 2013. The long-term Multicenter observational study of dabigatran treatment in patients With atrial fibrillation (RELYABLE) Study. Circulation 128:237-43. doi: 10.1161/circulationaha.112.001139.

47. Ho MH, Ho CW, Cheung E, Chan PH, Hai JJ, et al. 2014. Continuation of dabigatran therapy in "realworld" practice in Hong Kong. PloS one 9:e101245. doi: 10.1371/journal.pone.0101245. eCollection 2014.

48. Jacobs A, Linn D, Sipe B, Heyerly A, Bokhart G. 2014. Evaluation of Reasons for Dabigatran Discontinuation in a Community Hospital and Anticoagulation Clinic. Hospital Pharmacy 49:115-6. doi: 10.1310/hpj4902-115.

49. Suzuki S, Otsuka T, Sagara K, Matsuno S, Funada R, et al. 2012. Dabigatran in clinical practice for atrial fibrillation with special reference to activated partial thromboplastin time. Circulation journal : official journal of the Japanese Circulation Society 76:755-7. doi: 10.1253/circj.CJ-11-1335.

50. Camm AJ, Lip GY, De Caterina R, Savelieva I, Atar D, et al. 2012. 2012 focused update of the ESC Guidelines for the management of atrial fibrillation An update of the 2010 ESC Guidelines for the management of atrial fibrillationDeveloped with the special contribution of the European Heart Rhythm Association. European heart journal 14:1385-413. doi: 10.1093/europace/eus305.

51. Katoh H, Nozue T, Asada T, Nakashima K, Kimura $\mathrm{Y}$, et al. 2014. Frequency and predictors of bleeding complications associated with anti-coagulant therapy using dabigatran in Japanese patients with atrial fibrillation. American Journal of Cardiovascular Disease 4:70-8. www.AJCD.us /ISSN:2160200X/AJCD0000693.

52. Desai J KJ, Weitz JI, Aisenberg J. 2013. Gastrointestinal bleeding with the new oral anticoagulants-defining the issues and the management strategies. Thrombosis and haemostasis 110:205-12. doi: 10.1160/TH13-02-0150. Epub 2013 May 23.

53. Reilly PA, Lehr T, Haertter S, Connolly SJ, Yusuf S, et al. 2014. The effect of dabigatran plasma concentrations and patient characteristics on the frequency of ischemic stroke and major bleeding in 
atrial fibrillation patients: the RE-LY Trial (Randomized Evaluation of Long-Term Anticoagulation Therapy). Journal of American College of Cardiology 63:321-8. doi: 10.1016/j.jacc.2013.07.104. Epub 2013 Sep 27.

54. Lubitz SA, Benjamin EJ, Ellinor PT. 2010. Atrial fibrillation in congestive heart failure. Heart failure clinics 6:187-200. doi: 10.1016/j.hfc.2009.11.001.

55. Zamiri N, Eikelboom J, Reilly P, Ezekowitz M, Oldgren J, et al. 2016. CHA2DS2-VASC versus HAS-BLED score for predicting risk of major bleeding and ischemic stroke in atrial fibrillation: insights from RE-LY trial. Journal of the American College of Cardiology 67:1889. https://doi.org/10.1016/S0735-1097(16)31890-3.

56. Roldan V, Marin F, Fernandez H, ManzanoFernandez S, Gallego P, et al. 2013. Predictive value of the HAS-BLED and ATRIA bleeding scores for the risk of serious bleeding in a "real-world" population with atrial fibrillation receiving anticoagulant therapy. Chest 143:179-84. doi: 10.1378/chest.12-0608.

57. Gallego P, Roldan V, Torregrosa JM, Galvez J, Valdes M, et al. 2012. Relation of the HAS-BLED bleeding risk score to major bleeding, cardiovascular events, and mortality in anticoagulated patients with atrial fibrillation. Circulation. Arrhythmia and electrophysiology 5:312-8.doi: 10.1161/circep.111.967000.

58. Jaspers Focks J, van Vugt SPG, Albers-Akkers MTH, Lamfers EJP, Bloem-de Vries LM, et al. 2016. Low performance of bleeding risk models in the very elderly with atrial fibrillation using vitamin $\mathrm{K}$ antagonists. Journal of Thrombosis and Haemostasis 14:1715-24. doi: $10.1111 /$ jth.13361. 